\section{Tratamento do Hipertiroidismo: O Que Realmente Há de Novo?}

$\mathrm{H}$ IPERTIROIDISMO É UMA DOENÇA de bastante gravidade que afeta substancialmente a qualidade de vida, principalmente quando ocorre em indivíduos de baixo nível socioeconômico e cultural. Incide aproximadamente em $2 \%$ das mulheres e $0,25 \%$ dos homens. É causado principalmente pela doença de Graves, entidade autoimune associada à imunoglobulina $\mathrm{G}$ que se liga e estimula o receptor de TSH, produzindo uma hiperatividade permanente da tiróide. Desse modo, a disfunção tiroidiana é a expressão clínica da perda de tolerância imunológica com característica hereditária, podendo ser desencadeada por fatores ambientais e stress. O desconhecimento da seqüência de eventos que leva à doença de Graves dificulta o seu tratamento específico.

Nos últimos 60 anos o tratamento do hipertiroidismo decorrente da doença de Graves contínua com as mesmas controvertidas opções: drogas antitiroidianas ou cirurgia ou iodo radioativo, como demonstra Andrade e cols (1) neste número dos ABE\&M. Todos os três tratamentos são efetivos e apresentam problemas e efeitos colaterais e, nenhum oferece uma cura absoluta da doença.

A maioria dos endocrinologistas europeus, japoneses e da América Latina preferem o tratamento com drogas antitiroidianas, diferentemente dos norte-americanos que indicam a terapia com iodo radioativo como primeira opção, sendo as drogas antitiroidianas freqüentemente indicadas em adultos jovens, adolescentes e na gravidez (2). Entretanto, atualmente tem-se indicado cada vez mais iodo radioativo na adolescência e adultos jovens (3) e a tiroidectomia subtotal é cada vez um tratamento menos indicado. A escolha da terapia permanece uma questão em aberto e tem-se observado o aumento do uso de iodo radioativo como tratamento definitivo do hipertiroidismo, como demonstra o artigo de Albino e cols (4) neste número dos ABE\&M. Desde 1941, inúmeros pacientes têm sido tratados com iodo radioativo, terapia de fácil administração, baixo custo e poucos efeitos colaterais. Entretanto, ainda existe muita relutância em recomendar esse tratamento, principalmente porque se encontra associado com hipotiroidismo, além da noção negativa da idéia de radiação. Outra razão é o efeito deletério do iodo radioativo na evolução da oftalmopatia da doença de Graves em alguns pacientes (principalmente nos fumantes) que necessitam de um período de tratamento com corticosteróides. Embora o uso dos corticosteróides diminua o risco de agravamento da oftalmopatia, este efeito não é observado em todos os casos. A principal indicação de iodo radioativo como tratamento inicial do hipertiroidismo parece restringir-se aos pacientes com grande risco de recidiva após um primeiro tratamento com drogas antitiroidianas, bócios volumosos, adultos jovens e pacientes que apresentam elevada e persistente concentração de anticorpo anti-receptor de TSH.

O reconhecimento de que as drogas antitiroidianas apresentam efeitos imunossupressivos, levaram a um crescente interesse por diferentes esquemas terapêuticos com o objetivo de diminuir a percentagem de recidivas (5). Entretanto, a remissão ocorre em 16 a $55 \%$ dos pacientes tratados

\section{editorial}

João Hamilton Romaldini 
com drogas antitiroidianas por 12 a 24 meses, independente da associação ou não de hormônio tiroidiano para diminuir a incidência de hipotiroidismo iatrogênico, facilitar a aderência e diminuir o custo. Uma segunda alternativa é a administração de altas doses de drogas antitiroidianas (por exemplo, metimazol em doses acima de $60 \mathrm{mg}$ ); entretanto, há um aumento dos efeitos colaterais o que impede a sua utilização sem uma vigilância constante.

A baixa aderência ao tratamento prolongado é um dos principais indicadores do insucesso do tratamento com drogas antitiroidianas. É o que conclui neste número dos ABE\&M, Nirschl e cols (6), onde a taxa de abandono de seus pacientes com hipertiroidismo em tratamento com drogas antitiroidianas foi de $36,6 \%$ e por este motivo grande parte dos pacientes não alcançaram o eutiroidismo. A aderência ao tratamento com drogas por longos períodos relaciona-se com as características do paciente (jovens, sexo feminino), sintomas da doença (oftalmopatia, ansiedade e intolerância medicamentosa devido ao grande número de comprimidos), nível socioeconômico e cultural. Em relação à aderência a tratamentos, demonstrou-se que em 1.346 pacientes com hipertensão arterial (7), 31\% suspenderam as drogas havendo uma associação com a idade dos pacientes (20 a 40 anos) e com a baixa escolaridade. Podemos inferir que esses fatores que contribuem para a não aderência são os mesmos encontrados nos pacientes com doença de Graves. Alguns modelos (Models of Situational Barred from Compliance) foram propostos para melhorar a aderência e em geral enfatizam que o medicamento deve ser administrado somente uma ou duas vezes ao dia e o retorno não muito longo. $\mathrm{O}$ médico deve usar expressões mais acessíveis à compreensão dos pacientes, evitar cientificismo, explicar detalhadamente (se possível por escrito) os principais benefícios e orientações do tratamento clínico. Cada consulta de retorno deve durar pelo menos 20 minutos e, finalmente, o médico ou a instituição deve manter contato permanente com o paciente (telefone, e.mail). Como sugere Nirschl e cols (6), a criação e a implantação de grupos de apóio e educação ao paciente certamente irão contribuir para diminuir a falta de aderência. Foi com este modelo implantado no Serviço de Endocrinologia do Hospital do Servidor Público Estadual de São Paulo, durante mais de 15 anos, que se obteve elevada taxa de remissão do hipertiroidismo (5).
A doença de Graves é causada por disfunção do sistema imune e recentemente seus mecanismos básicos tornaram-se mais compreensíveis. Sabe-se que respostas específicas das células foliculares da tiróide, que expressam moléculas da classe II, estimulam a produção de diversas citocinas (interleucina- 1 , fator de necrose tumoral alfa, interleucina- 6 e prostaglandinas E) bem como células de adesão. Deste modo, o futuro desenvolvimento de drogas imunossupressoras mais dirigidas à imunidade tiroidiana provavelmente terão um substancial efeito no tratamento da doença de Graves. Como ocorre em outras doenças autoimunes, a análise da resposta celular aos auto-antígenos e a identificação dos determinantes das células T poderão induzir a tolerância imunológica ao receptor de TSH em indivíduos predispostos.

Até este momento a escolha do tratamento necessariamente deve refletir a opinião e experiência do clínico. O paciente deve sempre ser informado das três formas de tratamento e dos vários esquemas, bem como de suas complicações e deve dar a sua preferência. Talvez, em um dia não muito distante, as três formas de tratamento para o hipertiroidismo sejam somente contadas como história.

\section{REFERÊNCIAS}

1. Andrade VA, Gross JL, Maia AL. Tratamento do hipertiroidismo da doença de Graves. Arq Bras Endocrinol Metab 2001;45(6):609-618.

2. Romaldini JH. Case selection and restrictions recommended to patients with hyperthyroidism in South America. Thyroid 1997; 7:225-31.

3. Sandrini R, França SN, Lacerda L, Graf H. Tratamento do hipertiroidismo na infância e adolescência. Arq Bras Endocrinol Metab 2001;45(1):32-36.

4. Albino CC, Takahashi MH, Senhonni Junior S, Graf $H$. Inquérito sobre 0 uso de iodo-131 no Brasil. Arq Bras Endocrinol Metab 2001;45(6):558-562.

5. Romaldini, JH, Bromberg N, Werner MC. Tratamento da doença de Graves com drogas antitiroidianas. Arq Bras Endocrinol Metab 1994;38(1):1-9.

6. Nirschl RA, Kater FR, Nascif SO, Vieira AEF, Ramos-Dias JC, Senger MH. Avaliação do intervalo de tempo e custo médio para a obtenção do eutiroidismo na doença de Graves tratada com drogas antitiroidianas em um hospital geral. Arq Bras Endocrinol Metab 2001;45(6):533-539.

7. Giorgi DMA. Tese doutorado, Faculdade de Medicina de Universidade de São Paulo, 1989. 